Cadernos de Clio, Curitiba, v. 9, nº 1, 2018

\title{
POSITIVISMO, DISTOPIA E O LUGAR DAS ARTES EM “PARIS NO SÉCULO XX”, DE JÚLIO VERNE
}

\section{POSITIVISM, DISTOPYAS AND THE PLACE OF ARTS IN “PARIS IN THE TWENTIETH CENTURY”, BY JULES VERNE}

\section{Luca Lima Iacomini ${ }^{1}$}

Resumo: As discussões acerca do progresso ganharam amplo espaço no século XIX, desde seus elogios, bem aproveitados pelo positivismo até suas críticas, como explorado pelas distopias científicas. O escritor de ficção científica Júlio Verne explorou essas discussões no romance "Paris no século XX", envolvendo outro aspecto: o lugar das artes. O artigo tem como objetivo explorar a forma como essas tendências aparecem, bem como a discussão sobre as artes. Verne cria uma narrativa em que o desenvolvimento industrial tomou conta da cidade francesa, mas em vez de adotar uma postura positivista, celebrando esse progresso, critica-o, a partir do personagem Michel, um artista com um olhar distópico para sua sociedade, visto que a arte deixou de ser valorizada, perdendo seu espaço para a ciência.

Palavras-chave: Júlio Verne; positivismo; distopia; lugar das artes.

Abstract: The discussions about progress had a huge space in the nineteenth century, from its accomplishments, utilized by the positivism, to its criticisms, as explored by the scientific distopyas. The scientific fiction writer Jules Verne explored those discussions in the novel "Paris in the Twentieth Century", which evolves another aspect: the place of arts. This paper intends to explore the way these currents appear, as well as the discussions about arts. Verne creates a narrative in which the industrial development took place of the French city, but, instead of adopting a positivist posture, celebrating this progress, he criticizes it, through the character Michel, an artist with a distopyan look to his society, as the arts began being devaluated, losing its spot for sciences.

Keywords: Jules Verne; positivism; distopya; place of arts.

${ }^{1}$ Graduando em História (Licenciatura e Bacharelado) pela Universidade Federal do Paraná. 


\section{Introdução}

A Europa dos séculos XVI e XVII vivia um tempo de profundas mudanças. O desenvolvimento da técnica, o descobrimento de novos continentes e a chegada da indústria e do capital em detrimento do feudalismo levavam a uma "ruptura entre o tempo religioso e o tempo do mundo" (GIAROLA et al., 2016: 63). De acordo com Flávio Raimundo Giarola, Joyce de Souza Santos e Letícia Almeida Ribeiro (2016: 63), essas mudanças abriram caminho para que, no século XIX, surgisse um novo gênero literário "que buscava prever as etapas posteriores da evolução do homem": a ficção científica.

Nesse gênero, o cientista era considerado agente ativo do progresso, criando futuros possíveis com o "aperfeiçoamento da humanidade". Os futuros projetados nesses romances seriam marcados pelo avanço tecnológico do homem. Os autores também observam que

O que pode ser percebido nesse tipo de literatura é um misto entre fantasia e realidade, no qual o escritor apenas concebe seu futuro imaginário a partir de seu próprio contexto histórico. (...) Ora exaltando a ciência, ora temendo suas realizações; ora aplaudindo a ousadia dos cientistas, ora lembrando os limites de sua profissão, a ficção científica foi sublinhando as mudanças nas representações do futuro ao longo dos últimos dois séculos (GIAROLA et al., 2016: 64).

Um exemplo de autores de ficções científicas do século XIX era Mary Shelley ${ }^{2}$, escritora de Frankenstein, romance publicado em 1818, que 
trata sobre a história de um cientista que tenta criar um ser humano e acaba por criar um monstro. Shelley não idealizava a ciência, mas questionava seus limites, estabelecendo que "se o cientista tentasse ultrapassar os limites prescritos por Deus, as consequências seriam desastrosas, bizarras e destruidoras" (GIAROLA et al., 2016: 66). Por essas características, o livro de Shelley costuma ser tomado como referência no gênero de ficção científica.

Outro renomado autor nesse sentido foi o francês Júlio Verne, autor de obras como 20.000 Léguas Submarinas, Volta ao mundo em 80 dias e Viagem ao Centro da Terra. Em suas obras, Verne permite um diálogo da ficção com o modelo de vida projetado por ideais tecnicistas europeus de seu tempo, comumente associados ao progresso. Segundo Delumeau (1997: 285), a ideia de progresso ganha seu espaço durante o período das Luzes, tornando-a um dos principais componentes do pensamento ocidental. Daniel Vecchio aponta para a diversidade de leituras acerca da figura de Júlio Verne no que diz respeito à sua produção literária. A discussão de estudiosos sobre o autor diz respeito à consideração ou não de que Júlio Verne seria o pai da ficção científica, a partir "das várias antecipações tecnológicas que ele teria realizado em suas obras" (VECCHIO, 2014: 2). Segundo Vecchio (2014: 7),

Em apenas uma dúzia de anos, Verne se tornara o autor que mais vendeu em seu século, além de ser atualmente o autor mais adaptado na história do cinema, com mais de 200 filmes

${ }^{2}$ Outros autores do período importantes para o gênero foram H. G. Wells, Edward Bellamy e Arthur Conan Doyle. 
extraídos de sua coleção. Apesar da fama e do lucro, ele nunca diminuiu o ritmo. Com uma incrível marca de 65 livros, Verne tentou retratar não somente a vida do futuro, mas toda a história da existência humana. O principal objetivo de sua obra era descrever o mundo não somente em termos planetários, mas considerando os homens em sua integridade.

A obra Paris no século $X X$ foi escrita em 1863 enquanto Verne tinha seus 35 anos e sua esposa havia acabado de dar à luz o filho Michel, que acabaria por ser o mesmo nome do protagonista. Naquele ano a França vivia sob o reinado de Napoleão III, iniciado em 1852 e que só terminaria em 1870, quando o mesmo seria deposto.

Segundo Baroni (2011: 320) a obra não foi "publicada no período por ser considerada muito sombria, característica essa que a torna bastante distinta das demais obras de Verne". Em 1986, Piero Gondolo della Riva, vice-presidente da Sociedade Júlio $V_{\text {erne }}^{3}$, encontra o romance nos arquivos particulares dos herdeiros de Pierre-Jules Hetzel, editor que recusou a publicação da obra. O romance, porém, só seria publicado em 1989. Segundo Maria Hermínia Laurel e José Carlos Mota (2019: 2),

Mais do que um romance sobre o que poderia ser Paris no século XX, o livro que Verne assim intitula apresenta-se a um leitor que somente poderá dele ter conhecimento já quase no final daquele século, sob uma dupla identidade: por um lado, como uma descrição de novos espaços urbanos ainda em

3 A Sociedade Júlio Verne foi criada para "resgatar a imagem e a memória do escritor. Após a morte de Verne, seu filho Michel, com quem o autor teve uma relação problemática, alterou textos que ainda não haviam sido publicados. Os manuscritos originais foram recuperados pela Sociedade Júlio Verne e lançados" (FERNANDES, BBC Brasil). 
construção ou já em pleno funcionamento e de outros espaços definitivamente condenados; por outro, como o palco do conflito entre os novos valores e aqueles que deixaram de fazer sentido nos espaços da Modernidade urbana. A publicação contemporânea aos acontecimentos narrados neste livro poderia ter dado ocasião a uma recepção menos positiva da parte dos leitores de então; a sua publicação tardia ter-lhe-á sido paradoxalmente benéfica pois, ao mesmo tempo que permitiu consolidar as transformações em curso na cidade, criou condições para o estabelecimento da distância temporal necessária à formulação de hipóteses críticas sobre a sua escrita e sobre o Paris imaginado por Verne.

Sobre o surgimento do romance em si, Baroni (2011: 313-314) faz menção a Ian Watt, que constata que na Inglaterra do século XVIII o aspecto realista da literatura aparece como característica que "torna o romance uma novidade". Esse realismo se daria pela ênfase dos romances na individualidade dos personagens. Compreendendo a literatura a partir das relações da narrativa com o contexto, de forma como demonstrado por Baroni, o trabalho tem como objetivo perceber as tendências do positivismo e das distopias científicas e identificar o lugar das artes no romance de ficção científica Paris no século $X X$.

\section{Sobre o Positivismo}

Para encontrar a aplicação desses pensamentos na obra de Verne, é primeiro preciso compreendê-los. O positivismo foi uma teoria desenvolvida por Auguste Comte que se utilizava de métodos empíricos para "descobrir as regras que governam a sucessão e a coexistência dos fenómenos" (GARDINER, 1969: 89). O positivismo pauta o domínio do 
conhecimento em fenômenos e nas relações entre os fenômenos. O método para tal seria aquilo que Comte chama de "física social", pela qual, segundo Patrick Gardiner (1969: 89), “culmina o movimento histórico constituído pelo sucessivo aparecimento da matemática, da astronomia, da física, da química e da biologia como "ciências positivas"”. Esse movimento científico faria parte de um processo de evolução da humanidade, que passaria por três estágios: Teológico, segundo o espírito humano buscaria em seres sobrenaturais a explicação para os fenômenos; Metafísico, que Gardiner (1969: 91) considera ser uma "simples modificação geral do primeiro", segundo o qual "os agentes naturais são substituídos por forças abstratas, verdadeiras entidades (...) concebidos como capazes de engendrar por eles mesmos todos os fenômenos observados", isto é, a natureza em si passa a explicar o mundo em que se vivia; e Científico, ou Positivo, em que o homem deixa de procurar a origem e o destino do universo e passa a utilizar-se do raciocínio para conhecer a causa de fenômenos e dedicar-se a descobertas. Os principais fenômenos a que Comte se refere ao elaborar a filosofia positivista são astronômicos, físicos, químicos e fisiológicos.

Gardiner (1969: 93) afirma que a filosofía positivista considera que os fenômenos estão subordinados a "leis naturais invariáveis cuja descoberta precisa e cuja redução ao menor número possível são o fim de todos os nossos esforços", sendo a investigação de causas primeiras ou finais irrelevante para a filosofia. Gardiner (1969: 93) cita como exemplo a lei da gravitação newtoniana, que nos mostra que 
toda a imensa variedade dos factos astronômicos nada mais é do que um mesmo e único facto considerado sob diversos pontos de vista (...) enquanto, por outro lado, este facto geral nos é apresentado como uma simples extensão de um fenómeno que nos é bastante familiar e que, só por isso, consideramos como perfeitamente conhecido: o peso dos corpos a superfície da terra.

A filosofia positiva poderia, então, substituir as filosofias teológica e metafísica, por sua superioridade intelectual, em um futuro próximo em que a ciência se torne a prioridade entre os homens. A relação entre esse tipo de pensamento e o romance de Verne será explicada adiante.

\section{Sobre as utopias e distopias}

A questão do progresso tem ligação também com a ideia da utopia. Vecchio (2014: 3) afirma que "A história das utopias até o século XVIII pode ser vista como a história de modelos ideais de sociedade", apontando que uma das influências para a história dos pensamentos utopistas data de 1516: a Utopia, de Thomas Morus. Vecchio constata que as obras consideradas utópicas, desde A República, de Platão, buscam apontar soluções para os problemas do contexto em que foram escritas. O termo "utopia" carrega em si uma ambiguidade, uma vez que há uma junção de dois termos provenientes do latim: o termo eu topia, que designaria um melhor lugar; e o ou topia, que designaria um não lugar. Desta forma, Morus estabelece que o melhor lugar é um não lugar, ou seja, é um lugar que ainda não existe. Albert Quantin (apud. DELUMEAU, 1997: 337) considera que desde que Thomas Morus 
situou (...) a sociedade feliz que sonhava no imaginário país de Utopia, cada um chama utopia qualquer concepção de futuro contrária à sua própria. Para as pessoas positivas, os utopistas são visionários que se alimentam de quimeras.

Segundo Delumeau (1997: 268), as utopias criaram a ideia de uma esperança de felicidade que a humanidade poderia alcançar. Os pensamentos utópicos surgiram em uma sociedade marcada por um pensamento cristão de uma história que segue o rumo da salvação eterna, sendo esse o fim da história. A ideia do progresso utópico ligado à felicidade aparece nas ideias de autores como Leibniz e Adam Smith. Ambos os autores colocavam, em seus escritos, a vontade divina da felicidade humana, mas divergiam do pensamento de cristãos milenaristas, que se apoiavam em uma leitura baseada no livro bíblico de Apocalipse para afirmar que, para se chegar à etapa final de paz no mundo, primeiro passava-se por "convulsões violentas, e até mesmo abalos planetários" (DELUMEAU, 1997: 273).

Segundo Vecchio (2014: 3), desde o século XVIII já se percebe nos meios literários e filosóficos a insatisfação do homem frente a escrita de lugares ideais. A utopia passaria a ser vista como uma racionalização que controlaria institucionalmente e ideologicamente a mente dos homens. Segundo o autor, o romantismo, na virada para o século XIX, apareceria como uma revolta do homem contra esses paraísos, que, segundo constata o autor, "não passam de meros castelos de areia" (VECCHIO, 2014: 3).

A partir desses pensamentos, surgiriam paródias dessas utopias, que consistiriam na ideia de que essas construções idealistas "levariam ao massacre", representando, desta forma, uma "ruptura do pensamento do 
progresso utópico iluminista" (VECCHIO, 2014: 3). A evolução científica alimentou várias utopias, mas a descrença nela a partir do século XIX - e de forma contínua nos séculos XX e XXI - gerou a distopia. Vecchio (2014: 4) ressalta que, apesar disso, a crença na utopia pela evolução científica nunca desaparece. Segundo o autor,

enquanto a utopia científica demanda uma atitude de maravilhamento através da ciência e seus cientistas, os escritores das distopias mostram uma crescente ambivalência em relação a sua disseminação através do estranhamento de um ser humano em um mundo desumano, tomado completamente pela industrialização e suas relações mecanicistas (VECCHIO, 2014: 5).

\section{Paris no século XX}

O livro tema deste trabalho conta a história de Michel Jérôme Dufrénoy, um jovem amante das artes que cresce na cidade de Paris já tomada pela industrialização. Michel busca seu espaço como artista em meio ao abandono das artes. Semelhante ao sentimento de Michel é o mencionado por Maria Stella Martins Bresciani (1985: 37) ao estudar a sensibilidade do homem diante da industrialização no século XIX, ao escrever: "Máquinas, multidões, cidades: o persistente trinômio do progresso, do fascínio e do medo. O estranhamento do ser humano em meio ao mundo em que vive". Sobre a situação do homem diante do mundo, Bresciani (1985: 49) comenta:

De criador das ciências e das artes, o homem regredia para a condição de simples pesquisador de causas e efeitos, seus 
cérebros reduzidos a moinhos-lógicos, que à semelhança dos moinhos mecânicos trituravam tudo o que viam pela frente.

Logo no primeiro capítulo do livro são apresentados os avanços no meio industrial, e a função da instituição de educação pública Sociedade Geral de Crédito instrucional no contexto. Nesse progresso, porém, alguns ramos do conhecimento eram priorizados, enquanto outros eram deixados de lado. Entre esses últimos estavam as belas letras (idiomas como o francês, o latim e o grego), enquanto entre os primeiros estavam: as matemáticas, a astronomia, a mecânica, a química e as ciências aplicadas.

Em premiação promovida pela Sociedade em junho de 1960, Michel receberia o "primeiro prêmio de versos latinos". Apesar de seu bom desempenho, o órfão Michel não tinha a admiração de seus ricos tios, Sr. Stanislas Boutardin e Srta. Athénaïs Dufrénoy.

Stanislas Boutardin, banqueiro e diretor da Sociedade das Catacumbas de Paris, aparece no livro como uma das representações do positivismo, visto seu apreço para com o progresso, conforme a passagem:

O Sr. Stanislas Boutardin era o produto natural daquele século de indústrias (...); homem extremamente prático, nada fazia que não fosse útil, conformando suas menores idéias ao útil, com um desejo incontido de ser útil que ia dar num egoísmo verdadeiramente ideal; unindo o útil ao desagradável (...); desprezava solenemente as artes, principalmente os artistas, para dar a entender que os conhecia; para ele, a pintura não ia além de água forte, o desenho da cópia, a escultura da fôrma, a música do apito das locomotivas, a literatura dos boletins da Bolsa (VERNE, 1995: 53). 
Igualmente eram a tia e o primo de Michel. A tia era guardadora de livros e administradora, enquanto o primo, Athanase Boutardin, seria o "coeficiente obtido" da multiplicação dos pais, sendo sócio da instituição bancária Casmodage e Cia. Athanase é descrito como "um homem desagradável, sem juventude, sem coração, sem amigos. Seu pai o admirava muito" (VERNE, 1995: 56). Já Michel “opõe-se, desde o início do romance, a tudo que se anuncia como inovador, que prometa felicidade nesse mundo futuro. Ele parece, aliás, completamente deslocado na nova paisagem urbana" (LAUREL; MOTA. 2019: 3). Assim era o mundo em que Michel vivia: intensa valorização do investimento industrial e desvalorização das artes. Isso porque nesse momento o mundo teria avançado, atingido certo progresso, e as artes seriam algo distante, pertencente ao passado. Logo, os tios e o primo de Michel representariam um ideal positivista na história. Conforme colocado por Laurel e Mota (2019: 8),

Se é um facto que as tendências artísticas de Michel não são bem vistas nesta família, toda a mecanização da casa parece contagiar, desumanizando-os, os seus habitantes e modos de vida, dos empregados aos donos da casa. A descrição da entrada de Michel nesta casa, a primeira refeição partilhada, bastam para o leitor compreender a que ponto foi banida qualquer nota afetiva pessoal neste cenário.

Sr. Boutardin, em uma conversa com Michel, expressa seu desprezo para com a poesia e afirma que Michel, ao dedicar-se aos versos latinos, comprometeria sua família rica. Decide, portanto, que seu sobrinho trabalharia na Casmodage e Cia, sob a supervisão de Athanase. 
Michel, invadido pela tristeza, resolve aproveitar seu último dia antes de começar a trabalhar lendo alguns livros. Nesse momento Verne esboça uma sociedade que deixa de lado o apreço pela literatura. Michel vai até à livraria das Cinco Partes do Mundo em busca da obra completa de Victor Hugo, sem sucesso, visto que a biblioteca possuía vários livros, mas raramente vendiam obras literárias. A poesia disponível estava invadida pela ciência, pela química e pela mecânica:

- Ah! - fez Michel interessado. - Vocês têm poesias modernas?

- Sem dúvida. E, entre outras, as Harmonias elétricas, de Martillac, obra laureada pela Academia de Ciências, as Meditações sobre o oxigênio, do Sr. de Pulfasse, o Paralelograma poético, as Ordes descarbonatadas...

Michel não havia conseguido continuar ouvindo e já estava na rua, aterrorizado, estupefato! Assim, aquele pouco de arte não escapara à influência perniciosa da época! A ciência, a química e a mecânica faziam irrupção no terreno da poesia! (VERNE, 1995: 62).

Após a decepção com a livraria, dirige-se à biblioteca imperial, onde pede ajuda a um bibliotecário para encontrar obras de autores do século XIX, e tem a surpresa de descobrir que esse mesmo bibliotecário era seu tio Huguenin, que mais tarde ocuparia um papel importante na vida de Dufrénoy.

$\mathrm{Na}$ Casmodage e Cia, Michel seria primeiramente encarregado de uma máquina de cálculos, com a qual não teria habilidade de trabalhar. Sua habilidade com a leitura, nesse momento, é aproveitada. O jovem é 
transferido para trabalhar com o Grande Livro, onde trabalharia com Sr. Quinsonnas. O Grande Livro

\begin{abstract}
tinha seis metros de altura; um mecanismo inteligente permitia direcioná-lo como um telescópio, para todos os pontos do horizonte; um sistema de delicadas passarelas, engenhosamente combinado, descia ou subia conforme as necessidades do escrivão (VERNE, 1995: 79).
\end{abstract}

Destaca-se novamente o encantamento com as tecnologias até na produção do Livro. O trabalho de Michel seria ditar em voz alta os artigos do jornal que seriam transcritos para o Grande Livro, pelo Sr. Quinsonnas, que, no início, o amedrontava, mas de quem mais tarde acabaria se tornando um grande amigo. Essa amizade surgiu em um momento em que Michel contava de sua vida para Quinsonnas, que responde que o pai de Michel, talentoso músico, havia sido seu mestre. Quinsonnas, fora do ambiente de trabalho, era um talentoso pianista.

Michel já não se amedrontava pela feição séria de Quinsonnas, tendo percebido que era uma forma de esconder o riso, que era proibido no ambiente de trabalho, para garantir a produtividade, demonstrando a preocupação para com a satisfação de necessidades do mercado acima do lazer. Em certo dia, os dois jovens jantam na casa de Quinsonnas, junto a Jacques Aubanet, um soldado também amigo de Quinsonnas. Percebe-se, na narrativa do jantar dos três, traços de distopias. Jacques considera-se um artista, ao afirmar que "se você suprime os pintores, não há mais pintura, se suprime os escultores, não há mais escultura, se suprime os músicos não há mais música, e se suprime os guerreiros não há mais guerras! Os soldados 
são artistas" (VERNE, 1995: 95). Até mesmo a música escrita e tocada por Quinsonnas ao piano estava diretamente ligada à ciência. A peça chamava-se $A$ Thiloriana, grande fantasia sobre a liquefação do ácido carbônico, sem ritmo ou melodia marcantes, mas de fora a pura e simplesmente "pintar a última experiência que custara a vida a [o químico Charles] Thilorier" (VERNE, 1995: 104).

Em certo momento, Michel resolve visitar o tio Huguenin, ocasião que não apenas fortaleceria seus laços com seu tio, mas também com seu antigo professor Sr. Richelot, através do qual conheceria sua neta Lucy, pela qual se apaixonaria. Na figura de Sr. Richelot Verne traria outro exemplo da desvalorização das letras: o professor teria apenas três alunos em sua turma de retórica.

Após aquele encontro, a vida de Michel começa a passar por dificuldades, a partir da demissão de Quinsonnas e Michel após acidente com o Grande Livro, em que Quinsonnas derramou tintas multicores sobre as páginas do Livro. Nessa ocasião, Michel começava a expressar o sentimento por Lucy, ao que Quinsonnas respondia com suas críticas às mulheres e ao casamento, em que se percebem novamente alguns aspectos distópicos, ao afirmar que a mulher já "não existiria mais como antes" (VERNE, 1995: 144), já que deixou de ter o vigor do passado, e que os relacionamentos matrimoniais estavam pautados na frieza entre os cônjuges.

Após o acidente, Quinsonnas sugere que os dois vão à casa de tio Huguenin para conversar sobre a situação de Michel, que, apesar da recente demissão, seguia com a ambição de ser artista. Quinsonnas e Huguenin 
argumentam sobre a impossibilidade de sustento na hipótese de Michel ser apenas um artista em um tempo de desvalorização da arte. Quinsonnas traz à tona sobre o quão deterioradas estavam a pintura, a escultura, a música, o romance e até mesmo o jornalismo. Michel argumenta que havia um ramo da arte que Quinsonnas não havia abordado: o teatro. Quinsonnas, que tinha contatos, escreve uma carta de recomendação a Michel para o Diretor do Armazém Dramático.

Aceito nesse novo emprego, Michel não se identifica com o trabalho. O próprio ramo do teatro estava se adaptando ao contexto: grandes obras teatrais estavam sendo alteradas. Mesmo tendo trabalhado nos departamentos de comédia, drama e musical, Michel percebe que não poderia mais permanecer trabalhando no Armazém e se demite.

Percebendo que estava largado ao acaso novamente, Michel visita Quinsonnas, que estava arrumando as malas para viajar para a Alemanha, e doa seu apartamento a Michel. Após uma emocionada despedida, Michel decide que escreveria e se dedicaria aos poemas. Tudo isso sem se esquecer de Lucy, a quem amava e por quem se sentia amado. A neta de seu professor aparece como a única esperança que o jovem tinha em um mundo que já o desapontava demais. Lucy se preocupava com seu avô, que passava a ter apenas um aluno na turma de retórica. A moça passava a temer a falência de Sr. Richelot.

Ao terminar seu livro coletâneo de poesias, o qual chamou de $A s$ esperanças, corre para os editores, mas nenhum aceitou publicar e nem mesmo ler o livro de Michel, diminuindo suas esperanças. O jovem já estava perdendo suas economias e cada vez menos via seu tio Huguenin e o 
Sr. Richelot. Em meio ao frio intenso de dezembro, o jovem resolve gastar suas últimas economias comprando um buquê de violetas meio murchas para dar de presente a Lucy. Ao chegar na casa de Sr. Richelot, porém, descobre que sua dificuldade financeira o impedia de fazer o pagamento dentro do prazo; Richelot havia sido preso.

Michel, desesperado, começa a correr pela cidade, "ao pensar que tudo o que amava neste mundo talvez estivesse sofrendo" (VERNE, 1995: 196). Em seus caminhos pela cidade, se aborrecia com o domínio da eletricidade sobre a cidade, desde as "lâmpadas elétricas e raios da mesma natureza" sendo projetados do ostensório do sacerdote na Catedral de Notre-Dame (VERNE, 1995: 200) até a presença de concertos elétricos ${ }^{4}$ (VERNE, 1995: 202).

Essa característica da descrição espacial nas obras de Verne é descrita por Carlos Jorge Figueiredo Jorge (2000: 23), que escreve:

O espaço, nas várias figurações e tratamentos que a acção humana efectua, apresenta-se ele próprio como carregado de sentido. Não só pelo tratamento icónico que lhe dá a pintura, mas também pelo arranjo que a arquitectura e o urbanismo criam com vista à habitabilidade e, mais modernamente, pelas novas possibilidades de representação que a fotografia e o cinema introduziram, a espacialidade como sentido parece ter-se inserido na cultura de uma forma sobrevalorizada, opondo-se à temporalidade. No tempo de Verne, quando o cinema estava ainda para nascer e a televisão era uma utopia (que, aliás, ele trata com antecipação), toda a iconicidade, tendo apenas uma teoria forte amplamente difundida, é a da

${ }^{4}$ Concertos em que duzentos pianos eram tocados a partir da corrente elétrica conduzida por um único artista. 
visão monocular de um observador contemplando uma paisagem que é representada como um conjunto de objectos, independentemente da sua origem, captados pelo olho humano.

Michel, portanto, aparece como um observador da paisagem urbana em um contexto de modernização. Essa característica das obras de Verne é ainda mais presente nas chamadas "Viagens Extraordinárias"5.

Por fim, Michel chega ao cemitério do Père-Lachaise, onde passa pelos túmulos de grandes poetas e artistas respeitados como os músicos Chopin, Cherubini, e Habeneck e Massé os escritores Balzac, Dellavigne, Souvestre, Bérat, Plouvier, Gautier e Saint-Victor. Chorando, deposita o buquê de violetas sobre o túmulo do poeta Alfred de Musset. A história não termina com um final feliz. A angústia toma conta do protagonista. Tomado pela desgraça, Michel desmaia pensando na cidade em que vivia e em sua amada Lucy, que havia também caído em sofrimentos. Percebe-se nesse último ato de Michel um saudosismo: Paris, que era a cidade de grandes artistas, havia se reduzido a apenas uma capital industrial.

5 "Viagens Extraordinárias" foi o nome dado à coleção de livros de Júlio Verne que incluem viagens como a trama principal, que inclui: Viagem ao Centro da Terra; Cinco Semanas em Balão; A Volta ao Mundo em Oitenta Dias; Da Terra à Lua; 20 000 Léguas Submarinas; Miguel Strogoff; Os Filhos do Capitão Grant: Na América do Sul; Um Herói de Quinze Anos; À Roda da Lua; O País das Peles; A Escola dos Robinsons; Aventuras de Três Russos e Três Ingleses. Sobre isso, ver: $<$ http://creatividades.rba.es/pdfs/pt/JV_JulioVerne_POR_Fasc0_2018.pdf $>$. Acesso em: 08 set. 2020. 


\section{Conclusões}

Nessa obra, Júlio Verne destaca uma forma como Paris estava se desenvolvendo tecnologicamente. Por meio de descrições visuais o autor pretende projetar uma imagem da realização do progresso no meio científico. Não se encontram, na obra, traços sobre o papel da religião; a fé estaria depositada na ciência.

Nomeando o protagonista do romance a partir do nome de seu próprio filho, Verne parece projetar suas próprias preocupações com relação ao lugar das artes em meio à industrialização. A família Boutardin é representada como crentes do progresso, compartilhando, portanto, os ideais positivistas, por serem apreciadores do grande avanço tecnológico que tomou a cidade. Esse progresso, descrito na obra desde o ambiente de trabalho até as ruas da cidade, é reverenciado positivamente pela sociedade em geral.

Michel, Quinsonnas, Richelot, Jacques e Hugueni, porém, são representações das distopias. Michel encontrava seu refúgio em meio ao caos na escrita de poesias e no amor a Lucy, ambos comprometidos com a supervalorização da ciência, devido à falência do personagem diante da não aceitação de seu livro e à falência do avô de Lucy, que já não mais tinha condição de lecionar retórica pela falta de interesse da sociedade parisiense no aprendizado da matéria. Verne coloca o personagem Michel como um observador desse progresso, que, em vez de vê-lo como algo positivo, o enxerga com um olhar distópico, visto que é um artista em uma sociedade que perdeu o apreço por todos os tipos de arte. 


\section{Bibliografia}

BARONI, Lana. Romance e ciência: a relação entre História e Literatura na sociedade oitocentista. In: Cadernos de Clio, Curitiba: UFPR, v. 2, 2011. pp. 311-322. Disponível

em: $<$ https://revistas.ufpr.br/clio/article/viewFile/40522/24727> Acesso em: 01 mai. 2019.

BRESCIANI, Maria Stella Martins. Metrópoles: as faces do monstro urbano (as cidades no século XIX). Revista Brasileira de História, n. 8-9, p. 35-68, 1985.

DELUMEAU, Jean. Quinta parte: A felicidade no horizonte. Uma antalogia de textos futuristas. In: Mil anos de felicidade. Uma história do paraíso. São Paulo: Companhia das Letras, 1997. pp. 268-337.

FERNANDES, Daniela. França celebra centenário da morte de Júlio Verne. $B B C$ Brasil. Disponível em: $<$ https://www.bbc.com/portuguese/reporterbbc/story/2005/03/050324_vern ecl.shtml>. Acesso em: 05 jun. 2019.

GARDINER, Patrick. "Comte (1798-1857)"; "A filosofia positiva e o estudo da sociedade"; "Política e Sociedade". In: _. . Teorias da História. Lisboa: Fund. Calouste Gulbenkian, 1969. pp. 88-103.

GIAROLA, Flávio Raimundo; SANTOS, Joyce de Souza; RIBEIRO, Letícia Almeida. Representações do futuro em livros e filmes de ficção científica: do positivismo do século XIX ao "exterminismo" da Guerra Fria. In: Tempos Gerais - Revista de Ciências Sociais e História - UFSJ. v. 5, n. 1. São João del-Rei, 2016. pp. 62-82. Disponível em: $<$ http://www.seer.ufsj.edu.br/index.php/temposgerais/article/view/1991>. Acesso em: 01 mai. 2019.

JORGE, Carlos Jorge Figueiredo. Jules Verne - O Espaço Africano nas Aventuras da Travessia. Lisboa: Cosmos, 2000. 
LAUREL, Maria Hermínia; MOTA, José Carlos. Cronótopos da Modernidade em Paris au XXe siècle, de Júlio Verne. In: Carnets. Deuxième série. Revue électronique d'Études Françaises - Association Portugaise d'Études Françaises (APEF), 2019. Disponível em: $<$ https://journals.openedition.org/carnets/9111>. Acesso em: 01 mai. 2019.

MORUS, Thomas. Utopia. Tradução de Anah de Melo Franco. Brasília: Editora Universidade de Brasília: Instituto de Pesquisa de Relações Internacionais, 2004.

VECCHIO, Daniel. Estudos introdutórios sobre a utopia e a distopia científica nas obras de Júlio Verne. In: Recorte. v. 11, n. 2. Revista eletrônica do Programa de Mestrado em Letras - Universidade Vale do Rio Verde, 2014. em:

$<$ http://periodicos.unincor.br/index.php/recorte/article/view/1917>. Acesso em: 01 mai. 2019.

VERNE, Júlio. Paris no século XX. Tradução de Heloisa Jahn. São Paulo: Ática, 1995.

Recebido em: 21/06/2019 Aceito em: 09/09/2020 